\title{
Research on Campus Football Cultural Connotations
}

\author{
Xingxing Liu, Dupin Xie
}

Nanchang Institute of Science \&Technology, Nanchang 330108,China

Keywords: Sports culture; Campus football; Football

\begin{abstract}
Based on the definition of the concept of campus football and campus football culture, this paper analyzes the cultural connotation, composition and the relationship between them. Culture is the essential attribute of campus football, and people oriented is the core of campus football culture construction. The campus football culture is the sum of the material culture, spiritual culture, system culture and behavior culture. Among them, the material culture is the foundation, the spiritual culture is the direction, the system culture is the guarantee, the behavior culture is the standard. Behavior culture is the core of the campus football culture. The value of students is the core of the construction of campus football behavior culture.
\end{abstract}

\section{Introduction}

Through expert interviews, combined with the present development situation of the campus football, put forward the basic concept of the campus football: The comprehensive development in the majority of students to collectively promote football related activities and mental health of students and cultivate qualified talents of all-round development for the purpose. Which involves several problems: first, the main places: whether the students into the campus football activities is the core standard to determine the properties of the campus football, to ensure students as participants in case activities can not be limited to the campus. Second, the scope: only when the number of students participating in football activities can reach a certain base, it can be called campus football. Third, target: the core problem of campus football is concerned with the all-round development of the students' physical and mental health and morality, and not simply the football talent cultivation. Fourth, the form of campus football in a variety of forms, including football games and other related various activities.

\section{Campus football culture}

Sports culture is the sum of human sports material, system and spirit culture, on the basis of the current culture of the most common classification methods, combined with the characteristics of the campus football, put forward the concept of the campus football culture: campus football culture is the sum of the campus football related material culture, spiritual culture, system culture and behavior culture.

\section{Culture is the essential attribute of campus football}

The essence of campus football is culture. Because the football project belongs to a kind of sports, and sports as a means of education and education itself belongs to the history of human social practice in the creation of material wealth and spiritual wealth. From this point of view, sports and education are the means to implement the culture, it is the specific culture. In other words, the real core of football is culture. Campus football is a combination of sports and education, it is the 
practice product of sports and education. Therefore, culture is the real core of campus football, is the essence of campus football, cultural construction is the core work of campus football.

From the point of view of the impact on people, the impact of culture is subtle, lasting, and sports as a simple project, the impact on the relative stage. Therefore, only when the rise to the height of culture, the impact of sports will be more intense and lasting. As a kind of cultural phenomenon, football has its unique charm and contains the cultural unity which can not be replaced. As a type of sports, football is the world's first big movement, it has a broad mass base, widely loved by people all over the world, which reflects the special status in the sport of football.

As a kind of cultural phenomenon, football has its unique charm and contains the cultural unity which can not be replaced. As a type of sports, football is the world's first big movement, has a broad mass base, widely loved by people all over the world, which reflects the special status in the sport of football. Except football and other sports are difficult to obtain universally loved by people all over the world, the world cup will be in more than 213 countries and regions broadcast, the audience covering the Americas, Europe, Asia, Africa, the vast majority of countries, and people watch the value of more than 4 times the total number of the population of the earth. Why football is so attractive. The fundamental reason is the unique cultural advantage of football: the unity of culture. This is a cultural unity beyond the differences in age, gender, color, race, social class and other aspects of the different groups, make it become a common language, universal can be said that football goes beyond the secular life, to become a senior cultural world unitary enjoyment, football is not just a sport, it is the most democratic project in all sports, democracy of the football project, the unity of culture is fundamentally. As Chirac said: football has become a universal language, it is beyond the bounds of society.

\section{Taking students as the core is the core of campus football culture construction}

The implementation of the campus football activities is the process of the football project, it is the process of football project practice to influence people and transform people, and it is also the process of people's active role in the development of football projects. For the campus football, more refers to the majority of young students to participate in the football activities, it can be said that the student is the core of construction of campus football culture, campus football activities to the majority of the young students. Of course, those people can also include sports teachers, principals, managers and other groups, but the basic goal of carrying out the quality education from the campus football, and football training point of view, compared with students, these people still marginalized students is the core of all people.

The health of students is the basic premise of students. The development of campus football activities is the inevitable requirement of the extensive, deep and sustainable development of campus football activities. Without the active participation of the majority of young people, campus football will become a piece of paper. The development of campus football activities, not open the students' physical and mental health development of the basic premise, should promote the healthy growth of students as the starting point and end point of all the work of the school.

Compared with the students, football is second. The development of football in the school, first of all to meet the basic needs of the quality of education for students, and secondly, should consider the sustainable development of the project itself. Should be fully aware of: to make the football project in the school air plant long-term development, and ultimately meet the basic goal of football talents, so as to Chinese football promotion service, first must be clear between the student and the football relation, the student is the first, the development of football project is second the. Of course, the first and the second football players are not contradictory opposites, but complementary 
dialectical unity. Without the active participation of the majority of young people in the school, the development of the football project will not be able to talk about, the football project in the school widely carried out, for the full implementation of quality education, improve the youth, the physical quality, teamwork spirit provides a powerful starting point. That is to say, the sustainable development of campus football and football should be based on the students.

\section{Cultural unity of material, spiritual, behavioral and institutional culture}

Campus football culture is a cultural unity composed of material culture, spiritual culture, behavioral culture and institutional culture. Among them, the material culture as the basic conditions for football activities, which belongs to the basic category of spiritual culture; more inclined to ideology, belongs to the category of objectives; the institutional culture is to standardize the campus football activities and develop and set up the basic guarantee conditions belongs to the category of culture; related behavior and norms and constraints of student football the activities of the basic norms of behavior, belongs to the category of. From the perspective of students, the behavior culture is directly related to the students. Therefore, it is considered that the behavioral culture is the core of the four cultures.

Material culture is the foundation. The campus football culture is divided into: football related venues and facilities and teachers. The facility is the basic condition for the long-term and stable development of the football project in the school. Teachers' strength is an important factor in the development of campus football, strengthening the construction of campus football teachers is the inevitable requirement of the development of campus football. Education departments at all levels should speed up the adjustment of teachers' structure.

Spiritual culture is the direction. Spiritual culture is mainly reflected in five aspects: the campus football as a student's holiday, the stage of the teacher, the window of the school, the name card of the city and the improvement of the brand value of the campus football activities. The construction of campus spiritual culture is the culture of football, the ideal state is to meet basic needs of teachers and students for the school football, is a cooperative should achieve the expectations of the development effect of target schools, city and other units on campus football with the unit; at the same time, but also ensure the campus football objective needs its own healthy and sustainable the development of the.

The promotion of the brand value of campus football is the basic premise of its spiritual culture. Football is a continuous activity in schools, city, the participants of individual or group ideology, and have a profound impact in the objective environment internal ideology formation, healthy and upward football culture represents a country, a city civilization degree, only in their own rich culture the connotation of the premise, to be able to assume corresponding responsibility.

Behavioral culture is the norm. From the point of view of people oriented, students are the core of the construction of campus football culture, while the behavior culture (mainly refers to the value orientation and behavior way) is directly related to students.

The core position. The behavior culture of campus football consists of three parts: value orientation, behavior mode and behavior environment. Among them, the value orientation of objectives, including the value of students to understand the basic concept of football and a student to participate in the football activities mental state; behavior is mainly composed of a football competition, in football activities etiquette and football related games; environment behavior mainly considers the school and city football a traditional football activities and the atmosphere, natural conditions and other factors.

The construction of students' value orientation is the core of the construction of Campus Soccer 
behavior culture. The value goal, the idea and the spiritual state all belong to the ideological category, is the most fundamental factor which affects the student behavior way. The value goal reflects the original motivation of students to participate in campus football activities. There are significant individual differences in the value goal of the students participating in football activities: fitness, making friends, interest, happiness, becoming a star, showing themselves, etc.. These objectives are long-term, relatively stable and not changing, but also temporary. The establishment of positive and active value goals has a profound impact on the long-term and sustained participation of football activities. The concept mainly refers to the students' understanding of the rules and characteristics of the elements of the football game. For example, the understanding of the basic rules of football project; for the football project in the technical, tactical, physical, psychological characteristics knowledge, etc.. The state of mind refers to the temporary orientation of the students' ideological consciousness when they participate in football activities. From the perspective of the timeliness of the impact on the behavior of students, the impact of the value goal and the concept has the characteristics of persistence and stability.

Behavior is the specific reflection of students' value orientation in the practice of campus football. The unity of the limit behavior itself by competition rules, etiquette and the rules of the game and many other rules and regulations, but the difference values reflect practice to behavior, will show great individual differences. Under the premise of the rules, the effective protection and even the development of students' individual differences is an important responsibility and content of the construction of Campus Soccer behavior culture. The behavior environment has a profound impact on the students' value orientation and behavior. The formation and cultivation of school, city football tradition, atmosphere and environment is very important for the smooth implementation of the campus football.

\section{Conclusion}

Culture is the essential attribute of campus football, and student oriented is the core of the construction of campus football culture. The campus football culture is the sum of the material culture, spiritual culture, system culture and behavior culture. Among them, the material culture is the foundation, the spiritual culture is the direction, the system culture is the safeguard, the behavior culture is the standard. The behavior culture is the core of the campus football culture, and the value orientation of the students is the core of the construction of the campus football culture. The construction of the campus football culture is to cultivate students' interest in sports and hobbies, efficient measures to form a good habit of physical exercise, is the comprehensive implementation of quality education, promote the sunshine sports and the construction of effective means of excellent campus culture. In the construction of soccer culture as a means to promote the pace of the construction of campus culture, the football activities become an important part of the campus cultural activities, be accompanied by the growth of students way of life, become an important carrier of students' spirit and the construction of school culture.

\section{References}

[1] Thu C Y, Ming X U, Da-Hong L I. A study of campus cultural connotation at higher vocational college based on cultivation of innovative talent[J]. Journal of Zhenjiang College, 2011.

[2] Research on the Meanings,Functions and Developments of College Campus Sports Culture[J]. Bulletin of Sport Science \& Technology, 2012.

[3] Xi-Shui L I. Study on the Culture Connotation of CUBA Collegiate Basketball League and 
Campus Basketball Culture Construction[J]. Journal of Changchun Normal University, 2007.

[4] Zhou J. Campus Landscapes of Xiaogan University and Its Cultural Connotations[J]. Journal of Landscape Research, 2012(10).

[5] Feng B C. Expression of Culture Connotation in the Landscape Design of Baise College[J]. Journal of Anhui Agricultural Sciences, 2010.

[6] Qiu Y H, Chen Y L. Cultural Connotation Expression in the Universities Campus Landscape Designs[J]. Journal of Huazhong University of Science \& Technology, 2007.

[7] Huirong, Zhao, Xiaozhen, et al. Cultural Connotation of Landscape Plants and Its Expression in Landscape Design[J]. International Journal of Technology Management, 2013:94-96.

[8] Ren X, Ye B, Liu Q. The Culture Connotation of Plants and Its Application in Landscape Construction[J]. Modern Landscape Architecture, 2015. 